\title{
Static and dynamic lung volumes and ventilation- perfusion abnormality in adult asthma
}

\author{
J. D. MAYFIELD, P. N. PAEZ, and D. P. NICHOLSON \\ Department of Medicine, Woodlawn Chest Division, University of Texas Southwestern Medical School, \\ 5323 Harry Hines, Dallas, Texas 75235
}

\begin{abstract}
Dynamic lung volumes (forced vital capacity, forced expiratory volume in $\mathbf{0 . 5}$ second and in 1.0 second), static lung volumes (total lung capacity, functional residual capacity, residual volume), and ventilation-perfusion relationships (alveolar-arterial oxygen tension difference, alveolar dead space ventilation to tidal volume ratio, arterial oxygen and carbon dioxide tension, and the fractional ventilation and perfusion relationship by the three-compartment lung model) were measured in adult asthmatics during the acute, recovery, and stable or asymptomatic phases of an asthmatic attack. Eighteen patients were studied during 20 separate asthmatic attacks.

The patients behaved in one of three ways with regard to total lung capacity (TLC): group I had an elevated TLC during the acute asthmatic attack which returned to normal, group II had a normal TLC throughout the attack, and group III had an elevated TLC that did not return to normal on recovery from the asthmatic attack. With the patients separated into the three groups, the other pulmonary function measurements, especially the measurements of ventilation-perfusion abnormality, were compared. There were no statistically significant differences of ventilation-perfusion abnormality between groups I, II, or III. There was a tendency for perfusion abnormality to be less during the acute phase of the asthmatic attack in patients with an elevated TLC (group I). The three-compartment lung model revealed the major abnormality in all groups to be an increased fraction of unventilated but perfused lung.
\end{abstract}

Asthma is manifested by a widespread narrowing of the airways which changes in severity either spontaneously or as a result of therapy (American Thoracic Society, 1962). The increase in airway resistance is associated with ventilationperfusion $(\mathbf{V} / Q)$ abnormalities which also reverse spontaneously or with therapy.

Several authors have correlated changes in the clinical status with dynamic lung volumes and with $V / Q$ abnormalities. The most common index of airway resistance, the forced expiratory volume in 1.0 second $\left(\mathrm{FEV}_{1.0}\right)$, correlates with the clinical condition, with the arterial oxygen tension $\left(\mathrm{PaO}_{2}\right)$ (Tai and Read, 1967 ; Palmer and Diament, 1969 ; McFadden and Lyons, 1968 ; Wilson et al., 1970 ; Palmer and Diament, 1968 ; Beale, Fowler, and Comroe, 1952), and with the alveolar-arterial oxygen tension gradient $\left(\mathrm{AaPO}_{2}\right)$ (McFadden and Lyons, 1968; Wilson et al., 1970), all of which are reflections of uneven ventilation with respect to blood flow. There is generally no abnormality in true veno-arterial shunt as measured by $\mathrm{AaPo}_{2}$ on $100 \% \mathrm{O}_{2}$, except in critically ill asthmatic patients (McFadden and Lyons, 1968 ; Rees, Millar, and Donald, 1968). Some observations suggest that the $\mathrm{PaO}_{2}$ may not improve in parallel with the $\mathrm{FEV}_{1 \cdot 0}$ (Rees et al., 1968).

Asthmatic patients also show abnormal distribution of ventilation (Bentivoglio et al., 1963 ; Heckscher et al., 1968 ; Ledbetter, Bruck, and Farhi, 1964 ; Woolcock, McRae, Morris, and Read, 1966 ; Fowler, Cornish, and Kety, 1952). Asthmatics usually have overall alveolar hyperventilation, although the ratio of physiological dead space ventilation to tidal volume (VD/VT) may be increased (Tai and Read, 1967; McFadden and Lyons, 1968); alveolar hypoventilation with elevated arterial carbon dioxide tension $\left(\mathrm{PaCO}_{2}\right)$ occurs only in severely ill asthmatic patients (McFadden and Lyons, 1968 ; Wilson et al., 1970); this observation is in contrast to patients with chronic bronchitis who tend to have an elevated $\mathrm{PaCO}_{2}$ at comparable levels of airway obstruction (Palmer and Diament, 1970).

Ventilation-perfusion studies with radioxenon reveal regional hypoperfusion associated with regional hypoventilation; but perfusion is usually 
decreased less than ventilation, leading to areas with low V/Q ratios (Bentivoglio et al., 1963 ; Heckscher et al., 1968). The extent of the radioxenon abnormality correlates with the extent of abnormality in helium mixing, $\mathrm{FEV}_{1 \cdot 0}, \mathrm{PaO}_{2}$, and $\mathrm{AaPo}_{2}$ gradient (Bentivoglio et al., 1963 ; Woolcock et al., 1966).

The magnitude of $V / Q$ abnormality has been reported to correlate also with changes of static lung volumes in asthma, especially to increases in residual volume to total lung capacity ratio (RV/TLC) (Palmer and Diament, 1969).

It has been found that serial measurements of static lung volumes (TLC, RV, functional residual capacity-FRC) during and after an asthmatic attack show several different patterns of abnormality, and that improvement in static volumes may not be reflected in simultaneous improvements in dynamic measurements such as the $\mathrm{FEV}_{1 \cdot 0} ; \dot{\mathrm{V}} / \mathbf{Q}$ abnormality was not measured in these studies (Woolcock and Read, 1966 ; Woolcock and Read, 1965).

The present study was undertaken to re-evaluate, with more recent techniques, the relationship of $\mathbf{V} / \mathrm{Q}$ abnormalities to changes in dynamic and static lung volumes during and after the asthmatic attack, and to correlate these changes with those of the clinical condition.

\section{METHOD}

PATIENTS Adult asthmatic patients, all of whom $\overline{\bar{s}}$ had been followed in the clinic for at least threeyears, were selected for study when a severe attacke of asthma required hospital admission. Eighteen patients were evaluated during the acute andrecovery stage of the attack, and while stable or asymptomatic. Clinical data for each patient aresummarized in Table $I$; an explanation of the three groups will be given later.

Two patients were studied during two separate asthmatic attacks, with similar findings. In order top avoid bias, the studies during one of the attacks only were included for statistical analysis. At the time of each of these evaluations the patient was given a clinical grade from 1 to 3 . Clinical grade $1 \longrightarrow$ the patient was dyspnoeic at rest or on minimalexertion; clinical grade 2 -the patient was dyspnoeics with normal aotivity; and clinical grade 3-the patient was dyspnoeic only on heavy exertion of was completely asymptomatic. Data of patients whob were studied twice at any clinical grade are presen $\stackrel{\mathbb{D}}{-}$ ted as a mean of the two estimates for analysis.

If the patient had an infiltrate on the chest radio-graph or if significant bronchial infection was thought to be present, the patient was not included in the study.

Pulmonary function testing Spirometry was per⿳亠丷厂 formed on a Stead-Wells 9-litre spirometer; forced vital capacity (FVC), forced expiratory volume in

T A B LE I

CLINICAL DATA

\begin{tabular}{|c|c|c|c|c|c|c|c|c|c|c|c|}
\hline Group & Patient & Age & Sex & $\begin{array}{c}\text { Height } \\
\text { (in) }\end{array}$ & $\begin{array}{c}\text { Weight } \\
\text { (Ib) }\end{array}$ & $\begin{array}{c}\text { Asthma } \\
\text { Duration } \\
\text { (yr) }\end{array}$ & $\begin{array}{c}\text { Family } \\
\text { History of }_{\text {Asthma }^{1}}\end{array}$ & $\begin{array}{l}\text { Eosino- } \\
\text { philia }^{2}\end{array}$ & $\begin{array}{l}\text { Allergy } \\
\text { Skinn } \\
\text { Tests }\end{array}$ & $\begin{array}{l}\text { Desensi- } \\
\text { tization }\end{array}$ & Steroids \\
\hline I & \begin{tabular}{|c|}
1 \\
2 \\
3 \\
4 \\
5 \\
6 \\
Mean \pm S.D.
\end{tabular} & $\begin{array}{c}52 \\
32 \\
37 \\
44 \\
16 \\
68 \\
42 \pm 18\end{array}$ & $\begin{array}{l}\mathbf{F} \\
\mathbf{F} \\
\mathbf{M} \\
\mathbf{F} \\
\mathbf{F} \\
\mathbf{M}\end{array}$ & $\begin{array}{c}66 \\
64 \\
71 \\
63 \\
60 \\
66 \\
65 \pm 4\end{array}$ & $\begin{array}{c}164 \\
112 \\
180 \\
165 \\
130 \\
132 \\
147 \pm 26\end{array}$ & $\begin{array}{c}7 \\
20 \\
28 \\
33 \\
9 \\
35 \\
22 \pm 12\end{array}$ & $\begin{array}{l}+ \\
+ \\
+ \\
+ \\
+ \\
+\end{array}$ & $\begin{array}{l}+ \\
+ \\
+ \\
+ \\
+ \\
+\end{array}$ & $\begin{array}{l}+ \\
+ \\
+ \\
0 \\
+ \\
0\end{array}$ & $\begin{array}{l} \pm \\
\pm \\
\pm \\
+\end{array}$ & $\begin{array}{l}+ \\
+ \\
+ \\
+ \\
+\end{array}$ \\
\hline II & $\begin{array}{c}7 \\
8 \\
9 \\
10 \\
11 \\
12 \\
13 \\
\text { Mean } \pm \text { S.D. }\end{array}$ & $\begin{array}{c}63 \\
66 \\
67 \\
69 \\
48 \\
25 \\
50 \\
55 \pm 16\end{array}$ & $\begin{array}{l}\mathbf{M} \\
\mathbf{M} \\
\mathbf{F} \\
\mathbf{F} \\
\mathbf{F} \\
\mathbf{M} \\
\mathbf{F}\end{array}$ & $\begin{array}{c}67 \\
70 \\
65 \\
63 \\
65 \\
67 \\
64 \\
66 \pm 2\end{array}$ & $\begin{array}{c}188 \\
151 \\
150 \\
143 \\
240 \\
119 \\
143 \\
162 \pm 40\end{array}$ & $\begin{array}{c}3 \\
15 \\
37 \\
49 \\
43 \\
12 \\
26 \\
26 \pm 17\end{array}$ & $\begin{array}{l}\bar{z} \\
+ \\
\pm \\
\pm \\
\pm\end{array}$ & $\begin{array}{l}+ \\
+ \\
+ \\
+ \\
+ \\
+ \\
+\end{array}$ & $\begin{array}{l}\mathbf{0} \\
\mathbf{0} \\
+ \\
\mathbf{0} \\
\mathbf{0} \\
+ \\
+\end{array}$ & $\begin{array}{l}\bar{z} \\
\overline{+} \\
\bar{z} \\
\overline{+}\end{array}$ & $\begin{array}{l} \pm \\
\pm \\
\pm \\
\pm \\
\pm \\
\pm \\
+ \\
+\end{array}$ \\
\hline III & $\begin{array}{c}14 \\
15 \\
16 \\
17 \\
18 \\
\text { Mean } \pm \text { S.D. }\end{array}$ & $\begin{array}{c}62 \\
36 \\
39 \\
31 \\
47 \\
43 \pm 12\end{array}$ & $\begin{array}{l}\mathbf{M} \\
\mathbf{F} \\
\mathbf{M} \\
\mathbf{F} \\
\mathbf{F}\end{array}$ & $\begin{array}{c}73 \\
64 \\
71 \\
63 \\
65 \\
67 \pm 4\end{array}$ & $\begin{array}{c}194 \\
100 \\
165 \\
111 \\
125 \\
139 \pm 39\end{array}$ & $\begin{array}{c}32 \\
4 \\
7 \\
25 \\
3 \\
14 \pm 13\end{array}$ & $\begin{array}{l}\overline{+} \\
\pm \\
\pm\end{array}$ & $\begin{array}{l}+ \\
+ \\
+ \\
+ \\
+\end{array}$ & $\begin{array}{l}0 \\
+ \\
+ \\
+ \\
0\end{array}$ & $\begin{array}{l}\bar{z} \\
\bar{z} \\
\bar{z}\end{array}$ & $\begin{array}{l}+\frac{2}{+} \\
+ \\
+ \\
+ \\
+\end{array}$ \\
\hline
\end{tabular}

1 Family history of asthma: + indicates the presence of asthma in one or more close relatives.

Eosinophilia: + indicates that the patient has demonstrated blood and sputum eosinophilia.

- Desensitization: + indicates that the patient was receiving desensitization injections regularly at the time of the study.

- Steroids: + indicates that the patient was on maintenance corticosteroids to control asthma. 
0.5 second $\left(\mathrm{FEV}_{0.5}\right), \mathrm{FEV}_{1.0}$, and inspiratory capacity (IC) were measured.

Functional residual capacity was measured with the volume body plethysmographic method described by Mead (1960); the TLC and RV were calculated using measured FVC and IC. All volumes are expressed in B.T.P.S.

Prediotions of normal values were obtained for FVC, FEV ..5, and FEV $_{1.0}$ (Miller, Johnson, and Wu, 1959) and for TLC, FRC, and RV (Goldman and Becklake, 1959).

Expired gas was collected for three minutes, with the patient at rest in a semirecumbent position breathing room air. Respiratory frequency was noted. Oxygen consumption, $\mathrm{CO}_{2}$ production, and minute ventilation were calculated in the customary way. Arterial blood was drawn with a heparinized syringe from an indwelling Cournand needle during the final minute of expired gas collection. Arterial pH, $\mathrm{PCO}_{2}$, and $\mathrm{Po}_{2}$ were measured immediately at $37^{\circ} \mathrm{C}$ on a Beckman Model 160 blood gas analyser calibrated with known gas mixtures. Alveolar ventilation, $\mathrm{AaPO}_{2}$ gradient, and $\mathrm{VD} / \mathrm{VT}$ ratio were calculated using the above data.

An estimation of $\dot{\mathbf{V}} / \dot{Q}$ inequality was calculated using the three-compartment lung model of Penman (1967) ; Workman et al. (1965). For this purpose anatomical dead space was measured by the method of Fowler (1948), as modified by Wilson, Jay, Richburg, and Evans (1956), with the patient sitting during resting tidal volume at a level comparable to the tidal volume measured with a Douglas bag. Anatomical dead space remained stable, within the limits of the method, and will not be considered further. The results of the three compartments by this method are expressed by three fractions: the fraction of lung that is ventilated but unperfused (Fup, v), the fraction of lung perfused but unventilated (Fuv, p), and the remainder of lung that is ventilated and perfused (Fvp). Fvp is equal to $1.0-$ (Fuv, p+Fup, v). For all calculations, arteriovenous oxygen difference was assumed to be 5 vol\%. The mean normal value for Fup, $v$ is 0.27 , and for Fuv, $p$ is 0.02 (Penman and Howard, 1966).

To analyse the results, 14 measured variables were used: clinical status graded 1 to 3 ; variables expressed as per cent of predicted are FVC, $F E \mathbf{1}^{\cdot 0}$, TLC, FRC, and RV; the ratios $R V / T L C$ and $\mathrm{VD} / \mathrm{VT}$ are expressed in per cent; the variables $\mathrm{AaPo}_{2}, \mathrm{PaO}_{2}$, and $\mathrm{PaCO}_{2}$ are expressed in $\mathrm{mmHg}$; and Fuv, $p$ and Fup, $v$ are expressed as per cent (calculated fraction $\times 100$ ).

The patients were recalled during remission, and 14 of the 18 patients were studied with an oesophageal balloon in place. Dynamic compliance was measured at the resting respiratory rate, with pressure difference between the mouth and oesophagus recorded simultaneously with integrated pneumotachograph flow. Maximum elastic recoil (MER) at TLC, with the glottis open, was recorded at the same time.

\section{RESULTS}

The patients were divided into three groups depending on the pattern of TLC change during the attack of asthma: group I patients had a high TLC during clinical grade 1 which returned substantially toward normal by clinical grade 3 ; group II patients had TLC values within the predicted normal range at each clinical grade; and group III patients had a modest elevation of TLC at clinical grade 1 that had not altered significantly by clinical grade 3 .

The means and pooled estimates of the standard errors for each of the 13 variables measured at each of the three clinical grades for groups I, II, and III are presented in Table II. Listed on the right are $\mathbf{P}$ values for each variable to determine the significance of the change between clinical grades within each group (Duncan, 1955 ; Harter, 1960 ; Kramer, 1956). Arterial blood pH was not included in the analysis since all values

T A B L E I I

MEAN VALUES ( \pm STANDARD ERROR) FOR PULMONARY FUNCTION TESTS AT EACH CLINICAL GRADE

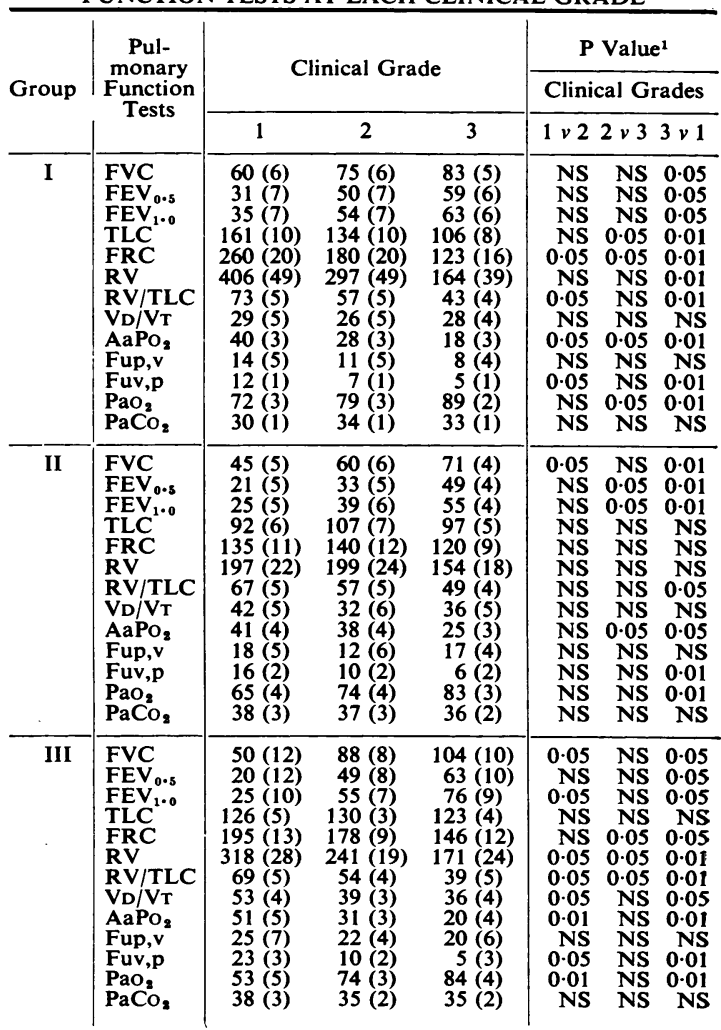

Method $(25,26,27)$.

NS means nonsignificant; 0.05 means $P \leqslant 0.05 ; 0.01$ means $P \leqslant 0.01$. 
were between 7.35 and $7 \cdot 45$, the normal range.

From Table II, the behaviour of group I can be summarized, in that all static lung volume (TLC, FRC, RV, RV/TLC) measurements showed decreases toward normal as the dynamic volumes (FVC, $\mathrm{FEV}_{0.5}, \mathrm{FEV}_{1 \cdot 0}$ ) increased toward normal. Clinical improvement was reflected with a greater degree of sensitivity by measurement of perfusion abnormality (Fuv,p, $\mathrm{AaPo}_{2}, \mathrm{PaO}_{2}$ ). Measurements of alveolar dead space ventilation (VD/VT, Fup,v, $\mathrm{PaCO}_{2}$ ) did not reveal any abnormality other than mild hyperventilation.

Group II showed an increase in dynamic lung volumes with clinical improvement without a comparable decrease in FRC. Residual volume tended to decrease but this was not significant; only the RV/TLC ratio decreased significantly. Perfusion abnormality, as in group I, was a good indicator of clinical improvement; the overall perfusion abnormality appeared greater in group II than in group I. Measurements of dead space ventilation did not change with the clinical grade, but values for VD/VT appeared greater at each clinical grade as compared with group I.

Group III, similar to groups I and II, showed increasing dynamic volumes with clinical improvement; and, as in group I, static volumes (FRC, RV, RV/TLC) decreased as the clinical condition improved, with the exception of TLC which remained greater than $120 \%$ of predicted. Perfusion abnormality, as with groups I and II, was a sensitive index of clinical improvement. The Fuv,p, $\mathrm{AaPo}_{2}$, and $\mathrm{PaO}_{2}$ at clinical grades 1 and 2 appeared more abnormal than similar measurements for group I. Group III was the only group to show significant improvement in ventilation abnormality as measured by $\mathrm{VD} / \mathrm{VT}$, although Fup,v did not show significant change and the $\mathrm{PaCO}_{2}$ was not abnormal.

With groups I, II, and III separated as above according to the pattern of TLC measured during the asthmatic attacks, statistical analysis of the remaining variables at each clinical grade was undertaken to see if there were any significant differences for any of these remaining variables between the groups, rather than within each group. Table III indicates only those results found to be significant, and allows the following observations :

1. The separation of groups I, II, and III by TLC has statistical significance at clinical grade 1, which persists between groups II and III in clinical grade 3. Thus, the separation of the three groups by behaviour of TLC is valid.

2. There is also a significant difference at clini-
T A B L E I I I

ANALYSIS OF PULMONARY FUNCTION VARIABLES BY P VALUE ${ }^{1}$ BETWEEN PATIENT GROUPS, AT EACH CLINICAI

\begin{tabular}{|c|c|c|c|c|}
\hline \multirow{2}{*}{$\begin{array}{l}\text { Clinical } \\
\text { Grade }\end{array}$} & \multirow{2}{*}{$\begin{array}{c}\text { Pulmonary } \\
\text { Function } \\
\text { Variables }\end{array}$} & \multicolumn{3}{|c|}{ Patient Groups } \\
\hline & & $1 v \mathrm{II}$ & II $v$ III & I $v$ III \\
\hline 1 & $\begin{array}{l}\text { FVC } \\
\text { FEV }_{\text {U.S }} \\
\text { TLC } \\
\text { FRC } \\
\text { RV }\end{array}$ & $\begin{array}{l}0.05 \\
0.05 \\
0.01 \\
0.01 \\
0.01\end{array}$ & $\begin{array}{c}\text { NS } \\
\text { NS } \\
0.01 \\
0.05 \\
0.01\end{array}$ & $\begin{array}{l}\text { NS } \\
0.05 \\
0.01 \\
0.05 \\
0.05\end{array}$ \\
\hline 3 & $\begin{array}{l}\text { FVC } \\
\text { TLC }\end{array}$ & $\begin{array}{l}\text { NS } \\
\text { NS }\end{array}$ & $\begin{array}{l}0.01 \\
0.05\end{array}$ & $\begin{array}{l}0.05 \\
\text { NS }\end{array}$ \\
\hline
\end{tabular}

1P value $(25,26$ and 27$)$

NS =non-significant; $0.01=P \leqslant 0.01 ： 0.05=P \leqslant 0.05$.

cal grade 1, between some or all groups, for theo static and dynamic lung volumes, which has largely resolved by clinical grade 3 . It is note-es worthy that at clinical grade 1 the behaviour of FRC and RV follow that of TLC.

3. There was no significant difference between the three groups within each clinical grade for the remaining variables, i.e., $R V / T L C, V D / V T \vec{s}$ $\mathrm{AaPO}_{2}$, Fup,v, Fuv,p, $\mathrm{PaO}_{2}$ and $\mathrm{PaCO}_{2}$, which mainly are estimates of abnormality of $V / Q$ or of gas exchange.

Intragroup correlation matrices for groups $I$ II, and III were constructed, but in the interes of brevity are not tabulated. Such analysiso showed, however, that clinical condition at each of the three clinical grades was strongly correla ted with FVC, $\mathrm{FEV}_{0.5}$, and $\mathrm{FEV}_{1.0}$ in all groups, and also with $\mathrm{PaO}_{2}, \mathrm{AaPo}_{2}$, and Fuv, p. The statie lung volumes TLC, FRC, RV, and RV/TLG. correlate with clinical grade in group $I$, but onl$\vec{P}$ the RV/TLC ratio correlated with clinical grades in group II. In group III, clinical grade correla ted with FRC, RV, and RV/TLC but not with TLC. The only measurement of ventilation abnors mality that correlated with clinical grade was the $\mathrm{VD} / \mathrm{VT}$ and this only in group III.

After the above studies were completed? patients from each group were called in fof studies of respiratory mechanics to see if any clearcut differences existed between groups I, IT and III. Fourteen of the 18 patients completed the study ; all of group I, four of seven of group II, and four of five of group III. Table IV shows results of specific dynamic compliance (dynamie compliance/FRC), maximum elastic recơ (MER), and coefficient of lung retraction (MER $\Phi$ TLC) for each of the patients studied. There were no differences between groups I, II, or III All studies of mechanics were performed wher the patients were either asymptomatic or onf mildly symptomatic. 
T A B L E IV

RESPIRATORY MECHANICS

\begin{tabular}{|c|c|c|c|}
\hline Group & $\begin{array}{c}\text { Specific Dynamic } \\
\text { Compliance } \\
\text { (1/cmH_0/FRC) }\end{array}$ & $\underset{\left(\mathrm{cmH}_{2} \mathrm{O}\right)}{\mathrm{MER}}$ & $\begin{array}{l}\text { Coefficient of } \\
\text { Lung Retraction } \\
\text { MER/TLC }\end{array}$ \\
\hline III & $\begin{array}{l}0.041(0.011) \\
0.037(0.025) \\
0.058(0.012)\end{array}$ & $\begin{array}{l}16 \cdot 3(2 \cdot 8) \\
17 \cdot 8(4 \cdot 9) \\
19 \cdot 0(5 \cdot 4)\end{array}$ & $\begin{array}{l}2 \cdot 68(0 \cdot 9) \\
2 \cdot 80(0 \cdot 7) \\
2 \cdot 78(1 \cdot 2)\end{array}$ \\
\hline
\end{tabular}

Normal range 0.038-0.072. Standard deviations in parentheses.

\section{DISCUSSION}

The asthmatic attack is associated with changes in static lung volumes, i.e., increased FRC and 'hyperinflation' which may be defined as an increased RV/TLC ratio. A study of the behaviour of static lung volume in asthmatic patients has been reported by Woolcock et al. (1966), who found that some patients dramatically increased their FRC and TLC during an asthmatic attack while other patients did not demonstrate significant changes. Woolcock et al. (1966); Woolcock and Read (1965) have postulated that the elevation of FRC and TLC may represent a uniform physiological response to airway narrowing, and aid in maintaining patent airways; they also considered the possibility that the helium dilution technique for measurement of lung volume, by excluding non-ventilated areas of lung, would have underestimated FRC in some patients. In the present study the volume body plethysmograph was used to measure lung volume, which negates the error found with gas dilution techniques, and yet variations in static lung volumes similar to those reported with the helium dilution method were found.

According to changes in TLC the patients in this study were separated into three groups. Group I had an elevated TLC which returned toward normal, group II had a normal TLC at all clinical grades, and group III had an elevated TLC at all clinical grades. With the patient groups separated in this manner, other parameters of pulmonary function, especially measurements of $\mathrm{V} / \mathrm{Q}$ abnormality, were compared. If, as has been suggested, elevation of FRC and TLC is functionally beneficial to the asthmatic, one would expect patients who could markedly increase the FRC and TLC (group I) to demonstrate less V/Q abnormality; however, there was no significant difference between groups I, II, and III with regard to $\mathrm{V} / \mathrm{Q}$ abnormality. There was only a tendency for groups II and III to have lower $\mathrm{PaO}_{2}$ and higher Fuv, $\mathrm{p}$ at clinical grade 1, but this was not statistically significant.
The estimation of $\forall / Q$ abnormality by the three-compartment method of Penman (1967); Workman et al. (1965) reveals the primary defect in all three groups to be an imbalance of perfusion as measured by Fuv, p, which correlated with clinical grade in all three groups. The threecompartment measurement of alveolar dead space ventilation, i.e., Fup, v, was normal in all groups at each clinical grade.

The basis for the variation in static lung volumes among the three groups is not evident from this study. The values for compliance and elastic recoil in patients from each group are presented in Table IV, but these measurements were made after the original study, and no measurements were made at a stage comparable to clinical grade 1 . The values for MER and coefficient of lung retraction for each group are generally low, but this is not surprising considering the mean ages of the groups $(41,43$, and 55 years) since MER decreases with age (Turner, Mead, and Wohl, 1968) and may remain low, even in younger patients, after an asthmatic attack (Gold, Kaufman, and Nadel, 1967). Serial studies of respiratory mechanics at each clinical grade of the asthmatic attack might reveal the basis for the observed variation in static lung volumes between the three groups.

We are indebted to Mrs. Joan Reisch for the statistical analysis, to Mr. Dan Cornelius, chief technician pulmonary laboratory, and to Mrs. Linda Cornelius for secretarial assistance.

This investigation was undertaken while J.D. M. was holding an NTRDA-ATS Fellowship.

\section{REFERENCES}

American Thoracic Society (1962). Definitions and classification of chronic bronchitis, asthma, and pulmonary emphysema. Amer. Rev. resp. Dis., 85, 762.

Beale, H. D., Fowler, W. S., and Comroe, J. H. (1952). Pulmonary function studies in $\mathbf{2 0}$ asthmatic patients in the symptom-free interval. J. Allergy., 23, 1.

Bentivoglio, L. G., Beerel, F., Bryan, A. C., Stewart, P. B., Rose, B., and Bates, D. V. (1963). Regional pulmonary function studied with xenon 133 in patients with bronchial asthma. J. clin. Invest., 42, 1193.

Duncan, D. B. (1955). Multiple range and multiple $F$ tests. Biometrics, 11, 1.

Fowler, W. S. (1948). Lung function studies. II. The respiratory dead space. Amer. J. Physiol., 154, 405.

_ Cornish, E. R., and Kety, S. S. (1952). Lung function studies. VIII. Analysis of alveolar ventilation by pulmonary $\mathrm{N}_{2}$ clearance curves. $J$. clin. Invest., 31, 40.

Gold, W. M., Kaufman, H. S., and Nadel, J. A. (1967). Elastic recoil of the lungs in chronic asthmatic patients before and after therapy. J. appl. Physiol., 23, 433. 
Goldman, H. I., and Becklake, M. R. (1959). Respiratory function tests. Amer. Rev. resp. Dis., 79, 457.

Harter, H. L. (1960). Critical values for Duncan's new multiple range test. Biometrics, 16, 671.

Heckscher, T., Bass, H., Oriol, A., Rose, B., Anthonisen, N. R., and Bates, D. V. (1968). Regional lung function in patients with bronchial asthma.J. clin. Invest., 47, 1063.

Kramer, C. Y. (1956). Extension of multiple range tests to group means with unequal numbers of replications. Biometrics, 12, 307.

Ledbetter, M. K., Bruck, E., and Farhi, L. E. (1964). Perfusion of the underventilated compartment of the lungs in asthmatic children. J. clin. Invest., 43, 2233.

McFadden, E. R. Jr., and Lyons, H. A. (1968). Arterialblood gas tension in asthma. New Engl. J. Med., 278, 1027.

Mead, J. (1960). Volume displacement body plethysmograph for respiratory measurements in human subjects. J. appl. Physiol., 15, 736.

Miller, W. F., Johnson, R. L., and Wu, N. (1959). Relationships between fast vital capacity and various timed expiratory capacities. J. appl. Physiol., 14, 157.

Palmer, K. N. V., and Diament, M. L. (1968). Hypoxaemia in bronchial asthma. Lancet, $1,318$.

(1969). Dynamic and static lung volumes and blood-gas tensions in bronchial asthma. Lancet, 1, 591. (1970). A comparison of pulmonary function in bronchial asthma and chronic obstructive bronchitis. Thorax, 25, 101.

Penman, R. W. B. (1967). Ventilation-perfusion inequality. Brit.J. Dis. Chest., 61, 12.
- and Howard, P. (1966). Distribution of pulmonary ventilation and blood flow in normal subjects and patients with chronic bronchitis. Clin. Sci., 30, 63 .

Rees, H. A., Millar, J. S., and Donald, K. W. (1968). A study of the clinical course and arterial blood-gas tensions of patients in status asthmaticus. Quart.J. Med., 37, 541.

Tai, E., and Read, J. (1967). Blood-gas tension in bronchia? asthma. Lancet, $1,644$.

Turner, J. M., Mead, J., and Wohl, M. E. (1968). Elasticity of human lungs in relation to age. J. appl. Physiol., 25 664.

Wilson, A. F., Surprenant, E. L., Beall, G. N., Siegel, S. C. Simmons, D. H., and Bennett, L. R. (1970). The signifi cance of regional pulmonary function changes in bron? chial asthma. Amer. J. Med., 48, 416.

Wilson, R. H., Jay, B. E., Richburg, P. L., and Evans, RG (1956). An evaluation of the single breath technique for measuring anatomic respiratory dead space with the nitrogen meter. Amer. J. med. Sci., 232, 67.

Woolcock, A. J., McRae, J., Morris, J. G., and Read, $\overrightarrow{J_{6}}$ (1966). Abnormal pulmonary blood flow distribution is bronchial asthma. Aust. Ann. Med., 15, 196.

- and Read, J. (1965). Improvement in bronchial asthm not reflected in forced expiratory volume. Lancet, $2 \mathcal{O}$ 1323.

Amer. J. Med., 41, 259.

Workman, J. M., Penman, R. W. B., Bromberger-Barnea, B Permutt, S., and Riley, R. L. (1965). Alveolar dea space, alveolar shunt, and transpulmonary pressures J. appl. Physiol., 20, 816. 